\title{
How Important Is Creativity? The Impact Of Age, Occupation And Cultural Background On The Assessment Of Ideas
}

\author{
Robert Klonoski, J.D., Mary Baldwin College, USA
}

\begin{abstract}
Since the early work of Schumpeter (1950), the role of the entrepreneur has been integrally linked with innovation, the bringing of a new idea to the firm to improve either its products or its processes. Schumpeter's entrepreneur is a person who has conceived of a new product or process or has recognized the value of new products or processes that have been invented elsewhere. The recognition of the value of a creative concept is a precondition to innovation. The role of the manager as a conduit for introducing potentially innovative concepts to the firm is to be able to recognize and appraise creative accomplishments, assess whether and how they might give the firm a competitive advantage, and to design the ways in which that might be accomplished. The current study seeks to identify how people view creativity as they age, and across occupations and cultures. The concept of creativity was found to vary with these three characteristics and changes qualitatively with age and occupation. Suggestions for further research are outlined.
\end{abstract}

Keywords: Creativity; Innovation; Entrepreneurship; Knowledge Management

\section{INTRODUCTION} suinn, Anderson and Finkelstein aptly characterized one of the key the challenges of engaging
businesses in knowledge economies: "Managing human intellect and converting it into useful
products and services is fast becoming the critical executive skill of the age." (2006, p. 71). Since the early work of Schumpeter (1950), the role of the entrepreneur has been integrally linked with innovation, the bringing of a new idea to the firm to improve either its products or its processes. Schumpeter's entrepreneur is a person who has conceived of a creative idea or has recognized the value of one that has been invented elsewhere. The recognition of the value of a creative concept is a precondition to innovation.

As a conduit for introducing potentially innovative concepts to the firm, the manager must be able to recognize and appraise creative accomplishments, assess whether and how they might give the firm a competitive advantage and to design the ways in which that might be accomplished. A number of studies have focused on the degree of creativity that managers possess and the relevance of this metric in bringing innovation to the firm (Reid, King and DeLorme, 1998; Simons, 1995, Homak, Lee and Riccio, 2005; Uhl-Bien, Marion and McKelvey, 2007). Other studies have considered the role managers play in opportunity assessment (Quinn, Anderson and Finkelstein, 1996). Kickul and Gundry (2001) saw opportunity assessment as mediating the interactive effects of managerial diversity and creativity, a process that influences the adoption of innovative practices. If a critical role of management, then, is in the recognition and assessment of creative achievement, it becomes important to understand the factors that shape and/or limit a manager's ability to perform this assessment.

Creativity has itself been associated with a wide range of cognitive styles (Guastello, Shissler, Driscoll and Hyde 1998) and has been correlated with age, work experience and travel experience (Zhang, 1999). It is more closely associated with a holistic mode of thinking than with one that is analytical (Zhang, 2002) and is positively correlated with psychosocial growth (Helson and Pals 2000). A model of creativity proposed by Martindale (1995) characterized it as a connectionist activity - the bringing together of concepts in ways that had not been anticipated 
beforehand. Dietrich (2004) created a typology of creative insights, systematizing the relationship between knowledge and creative thought, and in doing so, suggested that this is a relationship that changes with both domain and age.

The current study seeks to further investigate the relationship of an ability to recognize and assess the value of creative thought with three demographic variables, and asks: Does the perceived value of creative thought change with age, occupation and cultural background?

Gundry, Kickul and Prather described two sets of individual capabilities needed by managers in order to build a creative organization: (1) conceptual skills, including visioning and generating ideas, and (2) individual attributes, including risk-taking and openness to new ideas (1994, p. 29). This study begins with an assessment of the literature on the effect of age, occupation and cultural background on creativity itself and continues with a review of works that have considered the conditions and circumstances under which people are or are not open to new experiences. A series of hypotheses concerning the value people place on creativity is then proposed and tested against data available in the World Values Survey database. Suggestions for further research are then offered.

\section{THE RELATIONSHIP OF CREATIVITY TO AGE, OCCUPATION AND CULTURAL BACKGROUND}

Coming into the 1970's and 1980's, writers often expressed a notion that Lehman (1960) identified as the common wisdom that creativity declined with age. Embodied in the statement that "Older men may be more scholarly, but they do not usually exhibit more originality than do younger ones" (Lehman, 1960, p. 134), creativity was felt to be the province of the young (Ruth and Birren, 1985). Moreover, this relationship was felt to be true across cultures and over time (Simonton, 1975). More recent studies, however, have begun to examine this relationship more closely and have viewed creativity not as operating on a linear scale, but as a multi-dimensional concept (Cohenshalev, 1992; Sassercoen, 1993).

\section{Age and Creativity}

Creativity may not advance or decline with age so much as it undergoes certain qualitative changes (Abra, 1989; Cohenshalev, 1992; Sassercoen, 1993; Helson, Agronick and Roberts, 1995). In a comparative study of younger and middle-aged adults, Reese, Lee, Cohen and Puckett (2001) found that the middle aged group performed better than their younger counterparts in terms of ideational fluency, flexibility and originality. Self-perception of creativity does not diminish with age (Reed, 2005), rather, as Dollinger and Dollinger (2003) described, the "self" becomes more uniquely individualistic and complex. Wisdom and creativity were found to be differentiated on the basis of personal and social aspects of a person's perceptions rather than on cognitive and intellectual aspects (Knight and Parr, 1999). This distinction is particularly relevant because creative temperament has been found to be relatively stable over a person's lifespan (Helson, Roberts and Agronick, 1995; Soldz and Vaillant 1999), as was the specific domain of creativity in which a person is likely to engage (Park, Lubinski and Benbow, 2007). Creative activity fosters a sense of competence, purpose and growth in youth as well as among older adults (Fisher and Specht, 1999).

Whether creative output declines with age is not entirely settled. Ng and Feldman (2008) found that age was largely unrelated to core task performance and creativity in training programs. Other studies have shown that quantitatively measured creative output declines with age while qualitatively measured output does not (Alpaugh, Parham, Cole and Birren, 2006; Shimonaka \& Nakazato, 2007). The qualitative measurements included assessments of fluency and originality scales of thinking ability. Christensen et al (2007) investigated the relationship of brain burden (i.e., atrophy) and measures of reserve (education, creativity and intelligence) and found no association between cognitive declines and brain burden. Roskos-Ewoldsen, Black and McCown (2008) identified two phases of creative activity - generating an idea and exploring the implications of that idea - and associated each with different cognitive processes. While the authors identified age-related declines in the first activity, there was no corresponding decline with age in the second (2008). In describing "mature creativity," Shimonaka and Nakazato (2007) found that openness to experience and practical problem solving were correlated with scores of creativity and that personality and problem-solving ability influence mature creativity. 
To the extent that people measure creativity by the number of new ideas they generate, then their perceptions of the role and value of creativity in their lives is likely to decrease with age. If, however, as people age they begin to define creativity as openness to experience and practical problem solving, then their self-assessments of the value of creativity should not vary significantly with age, which leads us to:

Hypothesis 1: People's perceptions of the importance of creativity vary with age.

\section{Creativity and Occupation}

People begin to form relationships between their personal identity and potential careers beginning at very early ages (Gottfredson, 1981; Sastre, Mullet and Semin, 1999). Social cognitive career theory holds that people select their careers partially on the basis of their expectations that aspects of their chosen professions will help them fulfill or reach their interests, abilities and goals (Lent, Brown and Hackett, 1994). This concept was elaborated by Collins, Harrison, Mason and Lowden (2011) who described how the use of creativity enables students to develop their professional socialization through a process of role identification.

The practical implications of this association have been demonstrated in three ways: First, organizational creativity may be viewed in four distinct stages: generation, conceptualization, optimization and implementation (Basadur and Basadur, 2011), each of which may be associated with particular occupational roles. Second, and as relates to job characteristics, job satisfaction, organizational commitment and productivity have been positively associated with the degree to which a person is able to express creativity through his or her work (McNeese-Smith and Crook, 2003; Kidder, 2006; Robinson and Beesley, 2010). And third, people whose energies are focused on the generation stage of creativity are more often found outside or on the periphery of business organizations than working for them (Basadur and Basadur, 2011).

Based on the association of occupational identification and creativity, it is proposed that:

Hypothesis 2: People's perceptions of the value of creativity vary with occupation.

Further, it is possible that there is an interactive effect between age and occupation within the context of this discussion. For those people whose occupations involve creative problem solving late into their careers, the value of creativity may be stronger as people age than for those people whose careers do not require the same. It is therefore proposed that:

Hypothesis 2a: At any given age, people's perceptions of the value of creativity may be modified by their occupations.

\section{Creativity and Cultural Background}

A number of studies have attempted to associate a national culture with inventiveness and/or innovativeness. One of the most commonly used systems of measures of cultural characteristics is that proposed by Hofstede and includes individualism versus collectivism, power distance, masculinity, uncertainty avoidance, and as was recently added, long term orientation (2010). While these metrics have received some criticism, notably by Ailon (2008), who suggested that Hofstede's foundational study was itself subject to many of the same cultural biases it was intended to expose, these cultural comparatives have been used in much cross-cultural research, and underlies further research done by House, Quigley and de Luque (2010), and Trompenaars and Turner (1997).

As Dennis (1993) posited, the number of new business ventures started in any one society are an indicator of that society's national creative effort. Shane (1992), for example, compared the number of invention patents per person to Hofstede's indexes of individualism and power distance and found individualistic and non-hierarchical societies to be the more inventive. Mueller and Thomas (2001) also associated innovativeness with individualism, arguing that an entrepreneurial orientation is based on an internal locus of control and low uncertainty avoidance. Likewise, Thatcher, Stepina, Srite and Liu (2003) found an indirect relationship between two aspects of culture uncertainty avoidance and power distance - and personal innovativeness. The Shane study was confirmed and 
expanded by Williams and McGuire (2010) who likewise compared patents per person to Hofstede's indexes of individualism and power distance and went on to compare the indicator to the remainder of the Hofstede metrics. The authors similarly found that individualistic countries were likely to have more patents per capita than collectivist countries.

Other aspects of societal structure have been related to innovativeness and inventiveness, some of which can be described in terms of social capital (Hendricks, 1999). Shane (1992), for example, argued that a rigid social hierarchy would act to decrease inventiveness, while societies that encourage open communication work to enhance it. Odeh (1994) described how in the Djamiat, an Arab industrial "university," the principles of professional efficiency, creativity, competence and entrepreneurial initiative are taught as core values. On the other hand, in examining the regulatory systems of Singapore, Carney and Zheng (2009) argued that conflicting government incentive systems undermine innovative activity resulting in a culture of risk aversion and a lack of creativity. National and cross-cultural factors influencing creativity, then, are varied and complex and cross-border comparatives should be made with the understanding that a national level of creativity may be the product of a confluence of cultural, economic, educational and technological factors.

Given this, we offer the following hypothesis:

Hypothesis 3: People's perceptions of the value of creativity vary with:

a. Individualism

b. Power Distance

c. Uncertainty Avoidance

d. Masculinity

e. $\quad$ Long Term Orientation

\section{Assessing Creativity / Openness to Experience}

Part of what shapes a person's ability to assess the value of creative thought may be his or her openness to it. As Barber (1997) argued, the intentional orientation of an audience to a speaker may be a determinative component of the listeners' receptivity to new ideas. In a longitudinal study of openness to experience, Roberts, Walton and Viechtbauer (2006) demonstrated that openness remains constant throughout adulthood but declines slightly after the age of 60, while Zimprich, Allemand and Dellenbach (2009) found that openness to experience was relatively invariant between middle-aged and older adults. Hennessey (1994) also found that judgments of the creativity of a product as well as the process used to create that product were consistent across cultures.

One factor which may help to influence a person's receptivity to new ideas is the person's innate intelligence. Education has been shown to increase work creativity (Ross and Mirowsky, 2006) and individual differences in cognitive ability were found to be predictive of creative potential in science and technology within populations that have advanced educational degrees (Park, Lubinski and Benbow, 2008). The receptivity to new ideas may not, however, be a linear function of absolute intelligence. Dialectical and relativistic thinking were positively correlated with creativity, while formal thinking was not (Wu and Chiou, 2008). Moreover, an ability to exert cognitive control in a context sensitive manner may be predictive of overall creative ability (Zabelina and Robinson, 2010).

\section{METHODOLOGY}

For this analysis, data were drawn from the most recent wave of the World Values Survey (WVS), which was conducted between 2005 and 2008. Data were retrieved from and processed on the WVS website (http://www.worldvaluessurvey.org). Country level values for cultural dimensions were retrieved directly from: http://www.geert-hofstede.com/, the website created by Geert Hofstede in which he shares some of the results of his research.

In this section there is an analysis of question V80 of the World Values Survey, namely: "Now I will briefly describe some people. Using this card, would you please indicate for each description whether that person is 
very much like you, like you, somewhat like you, not like you, or not at all like you? Q: It is important to this person to think up new ideas and be creative. The questions called for a Likert scale response which was then converted into an index value (as described in Appendix A) so that results could be compared across the demographic indexes. The answers to the question are sorted by demographic data including age, occupational categories and country of residence. The occupational categories include categories of jobs, as well as descriptors of the degree to which those jobs are characterized by routine or manual tasks, and whether they are carried out independently or under close supervision.

\section{RESULTS}

The data indicates that the perception that it is important to think up new ideas and be creative declines with age. The data also indicate that the importance of thinking of new ideas varies greatly with occupation. Those employed as professionals as well as managers - regardless of the size of the organization- placed the highest value on creativity; the lowest values were ascribed by semi-skilled, unskilled, and agricultural workers.

The characterization of the tasks performed on a job as non-manual versus manual, non-routine versus routine and independently performed versus closely supervised are also correlated with the perceived importance of creativity. In general, non-manual labor and non-routine work are more positively associated with the perceived importance of creativity than manual labor and routine work. Also, work that is performed independently versus that which is performed under close supervision is also more closely correlated with the perceived importance of creativity.

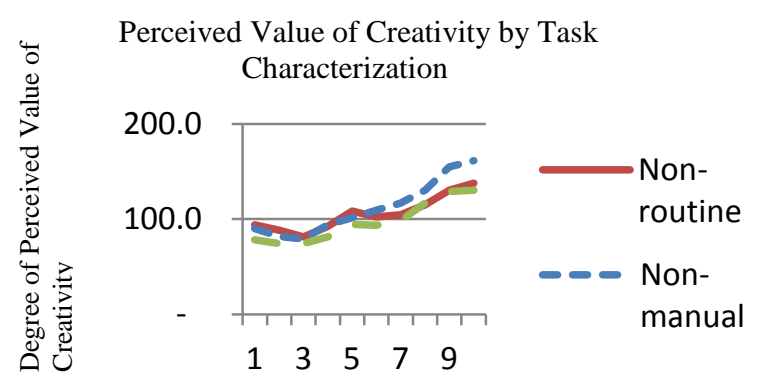

Degree to which a job is assessed as non-routine, non-manual, or performed independently (1=low, 10=high).

World Values Survey, 2005-2008

$\mathrm{n}=47.5 \mathrm{~K}$

With respect to Hofstede's cultural indicators, the perceived value of creativity was not correlated with power distance, individualism, masculinity or uncertainty avoidance. It did, however, have a negative correlation with long term orientation, albeit with a medium effect size.

\section{DISCUSSION}

In answering the question of whether it is important for a person to "think up new ideas and be creative," each respondent was being asked to assess the value of creativity in his or her own life. If creativity were needed in order for another person to effectively function in the role of the respondent, then creativity would likely be identified as a valuable and needed trait. For most respondents, the test of creativity is likely to be consistent with the commonly held definition of creativity, namely, that of having the ability to bring something new into existence, or to produce something through imaginative skill (American Heritage, 1982).

The question posed by the World Values Survey does not differentiate between the phases of creative activity - from generating an idea to exploring its implications - as were described by Roskos-Ewoldsen, Balck and McCown (2008). The second half of the definition offered by these authors is one that is more often associated with 
innovation than invention. For managers and professionals, it may be the linking of two disparate ideas or the reapplication of an idea seen elsewhere to the context of one's own environment that defines the "new."

In the context of management literature, the distinction between inventiveness and innovation is sometimes blurred. With respect to education, Ellis (2011) defined creativity as the perception and analysis of opportunities for learning; Hill and Johnson (2003) refer to "applied creativity" (2003, 221-222) to characterize innovation. Organizational creativity has been defined to include aspects of novelty as well as usefulness of their outputs (Amabile, 1983, Runco, 2004, Simonton, 2000a). For these authors, the creativity of an idea is found in the interplay of the newness of an idea and its practical applications; the value of a creative input is measured by its usefulness. Similarly, Basadur and Basadur (2011) split organizational creativity into stages beginning with generation and conceptualization and ending with optimization and implementation. The authors found that people focused on the generation stage of creativity are more commonly found on the periphery of organizations than within them, but also characterized the evaluation of the usefulness of an idea and its adaptation to the firm as the creative role of managers. The manager or professional, then, may be operating from a different conceptual basis than the nonmanagerial and non-professional population.

\section{The Hypotheses}

The first hypothesis - that people's perceptions of the importance of creativity vary with age - was supported by the data. Aging is associated with declines in certain types of brain activities including creative output as measured by the number (as opposed to the quality) of new ideas that are generated (Shimonaka and Nakazato, 2007; Roskos-Ewoldsen, Black and McCown, 2008). That a person would be willing to explore the implications of a new idea implies that the idea has first passed through a threshold - that it has been recognized as potentially having some value. The ability to be innovative, then, may not decline as rapidly with age as does the ability to be inventive. The "mature creativity" described by Shimonaka and Nakazato (2007) envisions an openness to experience that may be enhanced through middle age (Reese, Lee, Cohen and Puckett, 2001).

The second hypothesis - that people's perceptions of the value of creativity vary with occupation - was also supported by the data. Those people who were employed as managers or professionals were more likely to identify creativity as important to someone acting in their occupational roles than were people employed in jobs as semi-skilled or unskilled labor. The association of the importance of creativity with people who characterize their work as non-manual, non-routine and independently conducted (i.e., not under close supervision) further helps to clarify these differences.

Importance of Thinking of New Ideas and Being Creative

\begin{tabular}{|c|c|c|c|c|}
\hline \multirow[b]{2}{*}{ Occupation } & \multicolumn{3}{|c|}{ Age } & \multirow[b]{2}{*}{ Total } \\
\hline & $15-29$ & $30-49$ & $50+$ & \\
\hline Professional / Manager & 146.0 & 130.6 & 117.1 & 128.6 \\
\hline Skilled/Semi-Skilled & 122.9 & 98.0 & 69.6 & 96.1 \\
\hline Administrative (non-mgr) & 119.0 & 107.7 & 70.0 & 101.1 \\
\hline Unskilled & 107.9 & 80.0 & 44.1 & 75.4 \\
\hline Total & 127.5 & 109.4 & 81.2 & 105.2 \\
\hline
\end{tabular}

See: Appendix B, Tables $1 \& 2$

Index calculation described in Appendix A.

For those people who are principally engaged in a profession or in managing a business, the concept of creativity may include creative problem solving. This association has been demonstrated with professional service firms (Hargadon and Bechky, 2006), as well as with executives (Richard, 2003). For executives, managers and professionals whose work may be characterized as non-manual, non-routine, and independently conducted, linking ideas that had never before been connected or that had not been used in the context of their own organizations defines entrepreneurism. 
Correlation of Hofstede's Cultural Indicia with Creativity Index

\begin{tabular}{|c|c|c|}
\hline & Correlation & Value of $r^{2}$ \\
\hline Power distance & -.08 & .01 \\
\hline Individualism & .12 & .02 \\
\hline Masculinity & -.19 & .04 \\
\hline Uncertainty Avoidance & -.34 & .12 \\
\hline Long Term Orientation & -.64 & .41 \\
\hline
\end{tabular}

See: Appendix B Table 3

Moreover, this is a distinction that persists throughout one's professional career. While the perceived value of creativity may decline over an adult's lifespan for all categories of employment, its value for managers and professionals remains above the average for the entire population for all age categories. Given this, hypothesis $2 \mathrm{a}-$ at any given age, people's perceptions of the value of creativity may be modified by their occupations - is supported by the data.

The survey results show little, if any, correlation between Hofstede's metrics of individualism, power distance, uncertainty avoidance and masculinity with the perceived value of creativity. Only the longer term orientation indicator showed a negative correlation with the perceived value of creativity, and this with a medium effect size.

The methodology employed by Shane (1992) as well as by Williams and McGuire (2010) was to compare patents filed per person at a country level to Hofstede's indexes of individualism, power distance, masculinity and uncertainty avoidance. A difficulty with using this method is that developed countries have an educational and technological framework for encouraging idea development as well as a legal structure for protecting its ownership. The more developed countries of North America and Europe tend to be individualistic rather than collectivist and so the association of individualism with invention may be bound to a level of economic development as much as it is to culture. Studies predicting the effect of culture on dependent variables that could be tied to a level of economic development might benefit from holding the level of economic development constant in making these comparisons (Klonoski, 2011). In this vein, Tiessen (1997) had argued that individualism and collectivism neither categorically encourage nor discourage entrepreneurship; rather, they may act to shape how the functions are accomplished.

Hypothesis 3 (a), (b), (c) and (d) - that people's perceptions of the value of creativity vary with individualism, power distance, uncertainty avoidance and masculinity - were not supported by the data. Hypothesis 3 (e), however - that people's perceptions of the value of creativity vary with long term orientation - was supported.

The negative correlation of long term orientation and the perceived value of creativity suggest that the introduction of new concepts to an environment implies that change is an anticipated consequence of creative input. While it may not be presumed that all new ideas lead immediately to environmental changes, the link between the generation of "useful" new ideas and their implementation may be inevitable in the longer term. A long term orientation rests more comfortably on a premise of stability than on an environment of innovation and change; placing a high value on creativity, then, may imply a short term orientation.

\section{Limitations}

The methodology employed in this study has several limitations. First, the World Values Survey question being analyzed here is one which asks respondents for a self-assessment of a personal value, and it does so across national and cultural lines. Second, only three of the myriad influences on creative assessment are analyzed. While the analysis of age, occupation and national culture are important contributions to our understanding the topic, nothing here is intended to suggest that other variables might not also contribute to it as well. Further, studies demonstrating differences in perceptions based on age are, by proxy, also based in cultures, economies and political events peculiar to each generation. A longitudinal analysis might provide a more accurate assessment of the impact of the age, occupation and national culture as well as other relevant independent variables on how managers assess creative ideas. 


\section{CONCLUSION}

While certain creative capacities decrease with age, the ability to appreciate, evaluate and make use of creative concepts lingers throughout adulthood. Viewed in this way, Bandura's assessment that "cognitive development is better analyzed in terms of specialized cognitive competencies than discrete uniform ways of thinking," provides a rationale for why innovative more so than inventive capabilities persist as people age (1989, p. 9). The taxonomies of creativity of Gundry, Kickul and Prather (1994) as well as Roskos-Ewoldsen, Balck and McCown (2008) both separated two distinct cognitive functions - the ability to generate a new idea and to explore its implications. The second of these two functions assumes an openness and receptivity to new ideas -- an ability to understand the process of creativity, its products or its application to an existing set of circumstances is a discrete cognitive function separate and apart from a new way of thinking. The first of the functions has generally been referred to as invention and the latter as innovation.

Those involved in innovation may appreciate its creative aspect more so than those whose routine, manual and supervised activities give them fewer opportunities to do so. Managers and professionals, perhaps more so than unskilled labor or administrative personnel, may be called upon to solve problems that had not been encountered before, to become increasingly more efficient in the work they manage, or to bring new products or services to market. The data taken from the World Values Survey shows that people employed as professionals and managers are the more likely than others to appreciate the value of creativity. While as a demographic category, professionals and managers may not be the most inventive group (Basadur and Basadur, 2011), their appreciation of the creative suggests that as a group they may be called upon to be the most innovative of the occupational categories. Similarly, they may be more likely than others to appreciate the challenge of problem solving and innovation and to associate these activities with creativity. The higher positive response to the survey question by managers and professionals tends to strengthen this association.

The data showed little association of creativity with national culture. Unlike prior studies, however, only one of the examined cultural characteristics was found to be associated with creativity, namely, that of short term orientation. While other investigations had shown that countries characterized as "individualistic" were more inventive than those that were "collectivist," these studies focused on the generation of new ideas across countries as measured by patent applications. Given that the current level of economic and technological development in individualistic countries is generally higher than that of collectivist countries, the results of these studies may be influenced by non-cultural contextual factors.

Further study would help to clarify and develop these issues. For example, a longitudinal study assessing inventive as distinct from innovative capabilities as people age, and across occupational, cultural and other pertinent characteristics would help to delimit how different groups of people identify and view creativity. If, as Quinn, Anderson and Finkelstein (2006) suggested, managing the flow of inventiveness to innovation is the next critical executive skill, the study of what shapes managers' capacities for inventiveness and innovation is worthy of much additional study.

\section{AUTHOR INFORMATION}

Robert Klonoski is an Assistant Professor of Business Administration at Mary Baldwin College in Virginia, USA. His research interests include educational technologies and work motivation. He has also taught at the University of the District of Columbia, the University of Virginia and has worked in the financial services industry. Professor Klonoski holds a B.S. in Finance from Fairfield University, an M.B.A. from the University of Connecticut, and a J.D. from Brooklyn Law School. He is currently completing his Doctorate in Management at the University of Maryland, University College. E-mail: rklonosk@mbc.edu

\section{REFERENCES}

1. Abra, J. (1989). Changes in creativity with age: Data, explanations and further predictions. The International Journal of Aging and Human Development, 28(2), 105-126.

2. Ailon, G. (2008). Mirror, mirror on the wall: Culture's consequences in a value test of its own design. Academy of Management Review, 33(4), 885-904. Downloaded from: http://www.aomonline.org 
3. Alpaugh, P.K., Parham, I.A., Cole, K.D. \& Birren, J.E. (2006). Creativity in adulthood and old age: An exploratory study. Educational Gerontology, 8(2), 101-116.

4. Amabile, T. (1982). Social psychology of creativity: A consensual assessment technique. Personality and Social Psychology, 43(5), 997-1013.

5. American Heritage Dictionary $2^{\text {nd }}$ ed. (1982). Boston, MA: Houghton Mifflin Company

6. Bandura, A. (1989). Social cognitive theory. In R. Vasta (Ed.), Annals of child development. Vol. 6. Six theories of child development (pp. 1-60). Greenwich, CT: JAI Press.

7. Barber, K. (1997). Preliminary notes on audiences in Africa. Africa, 67(3), 347-362. doi: 10.2307/1161179

8. Basadur, M. \& Basadur, T. (2011). Where are the generators? Psychology of Aesthetics and Creativity and the Arts, 5(1), 29-42. doi: 10.1037/a0017757

9. Carney, R.W. \& Zheng, L.Y. (2009). Institutional (dis)incentives to innovate: An explanation for Singapore's innovation gap. Journal of East Asian Studies, 9(2), 291-319.

10. Christensen, H., Anstey, K.J., Parslow, R.A., Maller, J., Mackinnon, A \& Sachdev, P. (2007). The brain reserve hypothesis, brain atrophy and aging. Gerontology, 53(2), 82-95. doi: 10.1159/000096482

11. Cohenshalev, A. (1992). Self and style: The development of artistic expression from youth through midlive to old age in the works of Ibsen, Henrik. Journal of Aging Studies, 6(3), 289-299. doi: 10.1016/08904065(92)90006-R

12. Collins, M., Harrison, D., Mason, R. \& Lowden, A. (2011). Innovation and creativity: Exploring human occupation and professional development in student education. British Journal of Occupational Therapy, 74(6), 304-308. doi: 10.4276/030802211X3074383958020

13. Dennis, W.J. (1993). Is the new entrepreneurial era over? Journal of Creative Behavior, 27(2), 112-129.

14. Dietrich, A. (2004). The cognitive neuroscience of creativity. Psychonomic Bulletin \& Review, 11(6), 10111026. doi: 10.3758/BF03196731

15. Dollinger, S.J. \& Dollinger, S.M.C. (2003). Individuality in young and middle adulthood: An autophotographic study. Journal of Adult Development, 10(4), 227-236. doi: 10.1023/A:1026003426064

16. Ellis, V. (2011). Recognizing professional creativity from a CHAT perspective: Seeing knowledge and history in practice. Mind, Culture and Activity 18(2), 181-193. doi: 10.1080/10749039.2010.493595

17. Fisher, B.J. \& Specht, D.K. (1999). Successful aging and creativity in later life. Journal of Aging Studies, 13(4), 457-472. doi: 10.1016/S0890-4065(99)00021-3

18. Gottfredson, L. S. (1981). Circumscription and compromise: A developmental theory of occupational aspirations. Journal of Counseling Psychology, 28(6), 545-579. doi:10.1037/0022-0167.28.6.545

19. Guastello, S.J., Shissler, S., Dirscoll, J. \& Hyde, T. (1998). Are some cognitive styles more creatively productive than others? Journal of Creative Behavior, 32(2), 77-91.

20. Gundry, L. K., Kickul, J. R., \& Prather, C. W. (1994). Building the creative organization. Organizational Dynamics, 22(4), 22-37.

21. Hargadon, A.B. \& Bechky, B.A. (2006). When collections of creatives become creative collectives: A field study of problem solving at work. Organization Science, 17(4), 484-500.

22. Helson, R., \& Pals, J.L. (2000). Creative potential, creative achievement and personal growth. Journal of Personality, 68(1), 1-27.

23. Helson, R., Roberts, B, \& Agronick, G. (1995). Enduringness and change in creative personality and the prediction of occupational creativity. Journal of Personality and Social Psychology, 69(6), 1173-1183.

24. Hendricks, J. (1999). Creativity over the life course: A call for a relational perspective. International Journal of Aging \& Human Development, 48(2), 85-111. doi: 10.2190/2566-WMYX-FJDU-4H9R

25. Hennessey, B.A. (1994). The consensual assessment technique: An examination of the relationship between rating of product and process creativity. Creativity Research Journal, 7(2), 193-208.

26. Hofstede, G., Hofstede, G. J., \& Minkov, M. (2010). Cultures and organizations: Software of the mind. New York, NY: McGraw Hill.

27. Hofstede, G. (n.d.) Geert Hofstede ${ }^{\mathrm{tm}}$ cultural dimensions. Retrieved from: http://www.geerthofstede.com/hofstede dimensions.php

28. Homak, S., Lee, D. \& Riccio, C.A. (2005). Test review: Delis-Kaplan executive function system. Journal of Clinical and Experimental Neuropsychology, 27(5), 599-609. doi: 10.1080/13803390490918444

29. House, R. J., Quigley, N. R., \& de Luque, M. (2010). Insights from Project GLOBE. International Journal of Advertising, 29(1), 111-139. Downloaded from: http:// www.internationaljournalofadvertising.com 
30. Kickul, J. \& Gundry, L.K. (2001). Breaking through boundaries for organizational innovation: New managerial roles and practices in e-commerce firms. Journal of Management, 27(3), 347-361. doi: 10.1016/S0149-2063(01)00095-2

31. Kidder, J.L. (2006). "It's the job that I love": Bike messengers and edgework. Sociological Forum, 21(1), 31-54. doi: 10.1007/s11206-006-9002-x

32. Klonoski, R. (2011). Work motivation, culture and economic development: Is work motivation shaped by its socio-economic context?. International Journal of Management and Information Systems, 15(4), 91-99.

33. Knight, A.J. \& Parr, W.V. (1999). Age as a factor in judgments of wisdom and creativity. New Zealand Journal of Psychology, 28(1), 34-47.

34. Lehman, H. (1960). The age decrement in outstanding scientific creativity. American Psychologist, 15(2), 128-134. doi: 10.1037/h0041844

35. Lent, R. W., Brown, S. D., \& Hackett, G. (1994). Toward a unifying social cognitive theory of career and academic interest, choice, and performance. Journal of Vocational Behavior, 45, 79-122.

36. Martindale, C. (1995). Creativity and connectionism. In S.M. Smith, T.B. Ward \& R.A. Finke (Eds.), The creative cognition approach, (pp. 249-268). Cambridge, MA: MIT Press.

37. McNesse-Smith, D.K. \& Crook, M. (2003). Nursing values and a changing nurse workforce: Value, age, and job stages. Journal of Nursing Administration, 33(5), 260-270. doi: 10.1097/00005110-20030500000002

38. Mueller, S.L. \& Thomas, A.S. (2001). Culture and entrepreneurial potential: A nine country study of locus of control and innovativeness. Journal of Business Venturing, 16(1), 51-75. doi: 10.1016/S08839026(99)00039-7

39. Ng, T.W.H. \& Feldman, D.C. (2008). The relationship of age to ten dimensions of job performance. Journal of Applied Psychology, 93(2), 392-423. doi: 10.1037/0021-9010.93.2.392

40. Odeh, I.A. (1994). The education of an industrial middle class in Arab-Islamic countries. Interchange, 25(3), 295-304. doi: 10.1007/BF0145945

41. Park, G., Lubinski, D. \& Benbow, C.P. (2007). Contrasting intellectual patterns predict creativity in the arts and sciences: Tracking intellectually precocious youth over 25 years. Psychological Science, 18(11), 948952. doi: 10.1111/j.1467-9280.2007.02007.x

42. Park, G., Lubinski, D. \& Benbow, C.P. (2008). Ability differences among people who have commensurate degrees matter for scientific creativity. Psychological Science, 19(10), 957-961. doi: 10.1111/j.14679280.2008.02182.x

43. Quinn, J.B., Anderson, P. \& Finkelstein, S. (1996). Managing professional intellect: Making the most of the best. Harvard Business Review, 74(2), 71-80.

44. Reed. J.C. (2005). Creativity: Self-perceptions over time. International Journal of Aging \& Human Development, 60(1), 1-18. doi: 10.2190/WM5Y-FHEM-CXQT-UEXW

45. Reese, H.W., Lee, L.J., Cohen, S.H. \& Puckett, J.M. (2001). Effects of intellectual variables, age, and gender on divergent thinking in adulthood. International Journal of Behavioral Development, 25(6), 491500.

46. Reid, L.N., King, K.W. \& DeLorme, D.E. (1998). Top-level agency creatives look at advertising creativity then and now. Journal of Advertising, 27(2), 1-16.

47. Roberts, B.W., Walton, K.E. \& W. Viechtbauer, W. (2006). Patterns of mean-level change in personality traits across the life course: A meta-analysis of longitudinal studies. Psychological Bulletin, 132(1), 1-25. doi: 10.1037/0033-2909.132.1.1

48. Robinson, R.N.S, \& Beesley, L.G. (2010). Linkages between creativity and intention to quit: An occupational study of chefs. Tourism Management, 31(6), 765-776. doi: 10.1016/j.tourman.2009.08.003

49. Roskos-Ewoldsen, B., Black, S.R. \& McCown, S.M. (2008). Age-related changes in creative thinking. Journal of Creative Behavior, 42(1), 33-59.

50. Ross, C.E. \& Mirowsky, J. (2006). Sex differences in the effect of education on depression: Resource multiplication or resource substitution? Social Science \& Medicine, 63(5), 1400-1413. doi: 10.1016/j.socscimed.2006.03.013

51. Rudowicz, E., Tokarz, A. \& Beauvale, A. (2009). Desirability of personal characteristics associated with creativity: Through the eyes of Polish and Chinese university students. Thinking Skills and Creativity, 4(2), 104-115. doi: 10.1016/j.tsc.2009.06.003 
52. $\quad$ Runco, M.A. (2004). Creativity. Annual Review of Psychology, 55, 657-687. doi: 10.1146/annurev.psych.55.090902.141502

53. Ruth, J. \& Birren, J. (1985). Creativity in adulthood and old age: Relations to intelligence, sex and mode of testing. International Journal of Behavioral Development, 8(1), 99-109. doi: $10.1199 / 016502548500800107$

54. Sassercoen, J.R. (1993). Qualitative changes in creativity in the $2^{\text {nd }}$-half of life: A life-span developmental perspective. Journal of Creative Behavior, 27(1), 18-27.

55. Sastre, M.T.M., Mullet, E. \& Semin, C. (1999). The cognitive map of occupations: Factor structure in a Spanish sample. European Journal of Psychological Assessment, 15(1), 57-61. doi: 10.1027/10155759.15.1.57

56. Schumpeter, J. (1950). Can capitalism survive? New York, NY: Harper \& Row.

57. Shane, S.A. (1992). Why do some societies invent more than others?. Journal of Business Venturing, 7(1), 29-46. doi: 10.1016/0883-9026(92)90033-N

58. Shimonaka, Y. \& Nakazato, K. (2007). Creativity and factors affecting creative ability in adulthood and old age. Japanese Journal of Educational Psychology, 55(2), 231-243.

59. Simons, R. (1995). Control in an age of empowerment. Harvard Business Review, 73(2), 80-88.

60. Simonton, D. (1975). Age and literary creativity: A cross-cultural and transhistorical survey. Journal of Cross-Cultural Psychology, 6(3), 259-277. doi: 10.1177/002202217563001

61. Simonton, D. (2000a). Creativity: Cognitive, personal, developmental, and social aspects. American Psychologist, 55(1), 151-158. doi: 10.1037/0003-066X.55.1.151

62. Simonton, D. (2000b). Creative development as acquired expertise: Theoretical issues and an empirical test. Developmental Review 20(2), 283-318. doi: 10.1006/drev.1999.0504

63. Soldz, S. \& Vaillant, G.E. (1999). The big five personality traits and the life course: A 45-year longitudinal study. Journal of Research in Personality, 33(2), 208-232. doi: 10.1006/jrpe.1999.2243

64. Thatcher, J.B., Stepina, L.P, Srite, M. \& Liu, Y.M. (2003). Culture, overload and personal innovativeness with information technology: Extending the nomological net. Journal of Computer Information Systems, 44(1), 74-81.

65. Tiessen, J.H. (1997). Individualism, collectivism and entrepreneurship: A framework for international comparative research. Journal of Business Venturing, 12(5), 367-384. doi: 10.1016/S0883-9026(97)811998

66. Trompenaars, F. \& Turner, C.H. (1998). Riding the waves of culture: Understanding diversity in global business, $2^{\text {nd }}$ ed. New York, NY: McGraw Hill

67. Uhl-Bien, M., Marion, R. \& McKelvey, B. (2007). Complexity leadership theory: Shifting leadership from the industrial age to the knowledge era. Leadership Quarterly, 18(4), 298-318. doi: 10.1016/j.leaqua.2007.04.002

68. Williams, L.K. \& McGuire, S.J. (2010). Economic creativity and innovation implementation: The entrepreneurial drivers of growth? Evidence from 63 countries. Small Business Economics, 34(4), 391-412. doi: $10.1007 / \mathrm{s} 11187-008-9145-7$

69. Wu, P.L. \& Chiou, W.B. (2008). Postformal thinking and creativity among late adolescents: A postPiagetian approach. Adolescence, 43(170), 237-251.

70. Zablina. D., \& Robinson, M. (2010). Creativity as flexible cognitive tool. Psychology of Aesthetics, Creativity, and the Arts, 4(3), 136-143.

71. Zhang, L.F. (1999). Further cross-cultural validation of the theory of mental self-government. Journal of Psychology. 133(2), 165-181.

72. Zhang, Z.F. (2002). Thinking styles and modes of thinking: Implications for education and research. Journal of Psychology, 136(3), 245-261.

73. Zimprich, D., Allemand, M. \& Dellenbach, M. (2009). Openness to experience, fluid intelligence, and crystallized intelligence in middle-aged and old adults. Journal of Research in Personality, 43(3), 444-454. doi: 10.1016/j.jrp.2009.01.018 


\section{APPENDIX A: World Values Survey Questions}

V80: Schwartz: It is important to this person to think up new ideas and be creative

Now I will briefly describe some people. Using this card, would you please indicate for each description whether that person is very much like you, like you, somewhat like you, not like you, or not at all like you? (Code one answer for each description): It is important to this person to think up new ideas and be creative; to do things one's own way.

Answers:

1. Very much like me

2. Like me

3. Somewhat like me

4. A little like me

5. Not like me

6. Not at all like me

\author{
-1. Don't know \\ -2. No answer \\ -3. Not applicable \\ -4 . Not asked in survey \\ -5. Missing; unknown
}

V242: Profession/job

In which profession/occupation do you or did you work? If more than one job, the main job? What is/was your job there?

Answers:

1. Employer/manager of establishment with 10 or more employed

2. Employer/manager of establishment with less than 10 employed

3. Professional worker

4. Supervisory Non-manual office worker

5. $\quad$ Non-manual office worker

6. $\quad$ Foreman and supervisor

7. Skilled manual

8. $\quad$ Semi-skilled manual

9. Unskilled manual

10. Farmer: has own farm

11. Agricultural worker

12. Member of armed forces

13. Never had a job

V244: Nature of tasks: Manual vs. Cognitive

Are the tasks you perform at work mostly manual or non-manual? Use this scale where 1 means "mostly manual tasks" and 10 means "mostly non-manual tasks".

Answers:

1. Mostly manual tasks

6. 6

7. 7

8. 8

9. 9

-1. Don't know

-2. No answer

-3. Not applicable

-4. Not asked in survey

-5. Missing; unknown

2. 2

$3 . \quad 3$

4.4

5.5

10. Mostly non-manual tasks

-1. Don't know

-2. No answer

-3. Not applicable

-4. Not asked in survey

-5. Missing; unknown 
V245: Nature of tasks: Routine vs. Creative

Are the tasks you perform at work mostly routine or mostly not routine? Use this scale where 1 means "mostly routine tasks" and 10 means "mostly not routine tasks".

Answers:

$\begin{array}{ll}\text { 1. } & \text { Mostly routine tasks } \\ \text { 2. } & 2 \\ \text { 3. } & 3 \\ \text { 4. } & 4 \\ \text { 5. } & 5\end{array}$

6. 6

7. 7

8. 8

9. 9

10. Mostly not routine tasks
-1. Don't know

-2. No answer

-3. Not applicable

-4. Not asked in survey

-5. Missing; unknown

V246: Nature of tasks: Independence

How much independence do you have in performing your tasks at work? Use this scale where 1 means "no independence at all" and 10 means "complete independence".

Answers:

$\begin{array}{lllll}\text { 1. } & \text { No independence at all } & 6 . & 6 & -1 \text {. Don’t know } \\ \text { 2. } & 2 & 7 . & 7 & -2 \text {. No answer } \\ 3 . & 3 & 8 . & 8 & -3 \text {. Not applicable } \\ \text { 4. } & 4 & 9 . & 9 & -4 \text {. Not asked in survey } \\ 5 . & 5 & 10 . & \text { Complete independence } & -5 \text {. Missing; unknown }\end{array}$

In order to create a single ordinal score for questions V80, V244, V245 and V246, the following formulas were employed:

V80: Index $=100 \times(($ Very much like me $x 3)+($ Like me $x 2)+($ Somewhat like me $)-($ A little like me $)-($ Not like me $x$ 2) - (Not at all like me x 3)) where values for question answers were expressed in terms of the percentage of valid responses given.

V244: Index $=100$ x $(($ Mostly manual tasks $)+(“ 2 ”$ x 2) $+(“ 3 ”$ x 3) $+(“ 4 ”$ x 4) + (“5” x 5) + (“6” x 6) + (“7” x 7) + $(" 8 " x$ 8) $+(" 9 " x$ 9) $+($ Mostly non-manual tasks x 10)) where values for question answers were expressed in terms of the percentage of valid responses given.

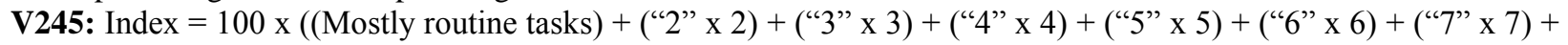
("8" x 8) + ("9" x 9) + (Mostly non routine tasks x 10)) where values for question answers were expressed in terms of the percentage of valid responses given.

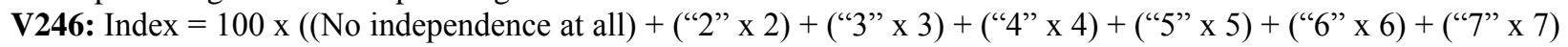
$+(" 8 " \times 8)+(" 9 " \times 9)+($ Complete independence $\times 10))$ where values for question answers were expressed in terms of the percentage of valid responses given.

Country Levels of Creativity: Index $=100 \mathrm{x}(($ Very much like me x 3$)+($ Like me $\mathrm{x} 2)+($ Somewhat like me $)-(\mathrm{A}$ little like me $)-($ Not like me x 2) - (Not at all like me x 3)) where values for question answers were expressed in terms of the percentage of valid responses given.

Retrieved from: http://www.wvsevsdb.com/wvs/WVSAnalizeQuestion.jsp. Results directly retrieved from the website and processes online. 


\section{APPENDIX B: Cross-Tabs}

Table 1 - Creativity Index by Task Characterization

\begin{tabular}{|c|c|c|c|}
\hline \multicolumn{4}{|l|}{ World Values Survey Database } \\
\hline $\begin{array}{c}\text { Breakdown by Characterization of Tasks / } \\
\text { Independence of Task Performance }\end{array}$ & Non-manual & Non-routine & Independent \\
\hline Scaled value $=1$ (manual, routine, or not independent at all) & 90.10 & 94.00 & 78.20 \\
\hline 2 & 81.50 & 88.10 & 74.40 \\
\hline 3 & 79.20 & 81.10 & 74.10 \\
\hline 4 & 93.90 & 92.10 & 81.10 \\
\hline 5 & 101.50 & 108.40 & 94.20 \\
\hline 6 & 109.00 & 102.10 & 93.50 \\
\hline 7 & 116.70 & 104.20 & 98.20 \\
\hline 8 & 130.40 & 115.00 & 116.60 \\
\hline 9 & 154.60 & 130.40 & 128.80 \\
\hline 10 (Non-manual, not routine, or completely independent) & 161.20 & 137.70 & 130.00 \\
\hline Total & 104.70 & 103.90 & 104.80 \\
\hline $\mathrm{N}=$ & $\mathbf{4 7 , 5 3 6}$ & $\mathbf{4 7 , 4 6 2}$ & $\mathbf{4 7 , 5 3 5}$ \\
\hline
\end{tabular}

Index calculation described in Appendix A.

Table 2: World Values Survey Database

V80: Schwartz: It is important to this person to think up new ideas and be creative

\begin{tabular}{|c|c|c|c|c|}
\hline Breakdown by Age and Employment & $15-29$ & $30-49$ & 50+ & Total \\
\hline Employer/manager of establishment with 10 or more employed & 144.90 & 140.00 & 115.40 & 130.90 \\
\hline Employer/manager of establishment with less than 10 employed & 151.70 & 143.10 & 135.10 & 142.00 \\
\hline Professional worker & 161.20 & 136.10 & 122.10 & 137.80 \\
\hline Supervisory Non manual -office worker & 147.40 & 121.00 & 105.60 & 119.90 \\
\hline Non manual -office worker & 119.00 & 107.70 & 70.00 & 101.10 \\
\hline Foreman and supervisor & 125.00 & 112.70 & 107.10 & 112.30 \\
\hline Skilled manual & 130.50 & 110.20 & 83.10 & 107.00 \\
\hline Semi-skilled manual worker & 115.30 & 85.80 & 56.00 & 85.10 \\
\hline Unskilled manual & 118.40 & 89.00 & 51.40 & 86.90 \\
\hline Farmer: has own farm & 107.10 & 108.10 & 79.40 & 96.80 \\
\hline Agricultural worker & 97.30 & 70.90 & 36.70 & 63.90 \\
\hline Member of armed forces & 143.00 & 116.00 & 88.70 & 116.40 \\
\hline Never had a job & 124.60 & 91.80 & 47.40 & 103.00 \\
\hline Other (cs) & 127.30 & 126.40 & 67.70 & 106.90 \\
\hline Total & 127.50 & 109.40 & 81.20 & 105.20 \\
\hline
\end{tabular}

Index calculation described in Appendix A.

$\mathrm{N}=44,063$ 
Table 3: Comparative of the Creativity Index to Hofstede's Cultural Indicators

\begin{tabular}{|c|c|c|c|c|c|c|c|}
\hline & $\mathbf{n}=$ & $\begin{array}{c}\text { Creativity } \\
\text { Index }\end{array}$ & $\begin{array}{c}\text { Power } \\
\text { Distance }\end{array}$ & Individualism & Masculinity & $\begin{array}{c}\text { Uncertainty } \\
\text { Avoidance }\end{array}$ & $\begin{array}{l}\text { Long Term } \\
\text { Orientation } \\
\end{array}$ \\
\hline France & 995 & 78.8 & 68 & 71 & 43 & 86 & \\
\hline Great Britain & 1,036 & 100.9 & 35 & 89 & 66 & 35 & 25 \\
\hline Netherlands & 1,043 & 110.0 & 38 & 80 & 14 & 53 & 44 \\
\hline Spain & 1,176 & 79.7 & 57 & 51 & 42 & 86 & \\
\hline United States & 1,215 & 91.3 & 40 & 91 & 62 & 46 & 29 \\
\hline Canada & 2,140 & 148.1 & 39 & 80 & 52 & 48 & 23 \\
\hline Japan & 1,038 & $(19.2)$ & 54 & 46 & 95 & 92 & 80 \\
\hline Mexico & 1,502 & 108.0 & 81 & 30 & 69 & 82 & \\
\hline South Africa & 2,964 & 176.9 & 49 & 65 & 63 & 49 & \\
\hline Australia & 1,391 & 80.2 & 36 & 90 & 61 & 51 & 31 \\
\hline Norway & 1,018 & 104.7 & 31 & 69 & 8 & 50 & 20 \\
\hline Sweden & 1,001 & 146.3 & 31 & 71 & 5 & 29 & 33 \\
\hline Argentina & 958 & 53.3 & 49 & 46 & 56 & 86 & \\
\hline Finland & 1,005 & 114.1 & 33 & 63 & 26 & 59 & \\
\hline South Korea & 1,199 & 17.7 & 60 & 18 & 39 & 85 & 75 \\
\hline Poland & 981 & 81.3 & 68 & 60 & 64 & 93 & 32 \\
\hline Switzerland & 1,240 & 126.7 & 34 & 68 & 70 & 58 & \\
\hline Brazil & 1,492 & 124.7 & 69 & 38 & 49 & 76 & 65 \\
\hline Chile & 955 & 133.3 & 63 & 23 & 28 & 86 & \\
\hline India & 1,593 & 144.8 & 77 & 48 & 56 & 40 & 61 \\
\hline Bulgaria & 926 & 29.2 & 70 & 30 & 40 & 85 & \\
\hline Romania & 1,546 & 90.3 & 90 & 30 & 42 & 90 & \\
\hline China & 1,919 & 39.1 & 80 & 20 & 66 & 30 & 118 \\
\hline Taiwan & 1,222 & 47.4 & 58 & 17 & 45 & 69 & 87 \\
\hline Turkey & 1,309 & 160.8 & 66 & 37 & 45 & 85 & \\
\hline Russia & 1,911 & 40.3 & 93 & 39 & 36 & 95 & \\
\hline Peru & 1,458 & 90.9 & 64 & 16 & 42 & 87 & \\
\hline Uruguay & 994 & 117.0 & 61 & 36 & 38 & 100 & \\
\hline Ghana & 1,521 & 206.1 & 77 & 20 & 46 & 54 & 16 \\
\hline Thailand & 1,528 & 37.5 & 64 & 20 & 34 & 64 & 56 \\
\hline Indonesia & 1,948 & 104.9 & 78 & 14 & 46 & 48 & \\
\hline Viet Nam & 1,383 & 98.8 & 70 & 20 & 40 & 30 & 80 \\
\hline Morocco & 1,162 & 156.1 & 70 & 46 & 53 & 68 & \\
\hline Iran & 2,652 & 134.6 & 58 & 41 & 43 & 59 & \\
\hline Trinidad & 1,000 & 123.1 & 47 & 16 & 58 & 55 & \\
\hline Malaysia & 1,201 & 88.0 & 104 & 26 & 50 & 36 & \\
\hline Mali & 1,501 & 167.8 & 77 & 20 & 46 & 54 & 16 \\
\hline Germany & 2,029 & 88.8 & 35 & 67 & 66 & 65 & 31 \\
\hline Total & $\begin{array}{l}70,804 \\
\end{array}$ & 104.6 & 60 & 45 & 47 & 65 & 49 \\
\hline \multicolumn{3}{|l|}{ Correlation } & -0.08 & 0.12 & -0.19 & -0.34 & -0.64 \\
\hline \multicolumn{3}{|l|}{ Value of $r^{2}$} & 0.01 & 0.02 & 0.04 & 0.12 & 0.41 \\
\hline
\end{tabular}

Index calculation described in Appendix A.

Hofstede indicators retrieved from: http://www.geert-hofstede.com 
NOTES 